had an unsympathetic tone, and had missed the point that the onus is on treatment services to make themselves accessible to women who may have chaotic lives. Our approach to care is crucial if we are to retain these women in treatment throughout pregnancy, and this support needs to flow seamlessly into the postnatal period.

There is a relationship between maternal methadone dose and severity of neonatal abstinence syndrome, but this is not a close one (Johnstone, 1998). The onset, duration and severity of neonatal abstinence syndrome is multi-factorial and related to the infant's metabolism, gestational age and central nervous system maturity. It is essential to work with parents to prepare them for the possibility of neonatal abstinence syndrome and to try to involve them in the management of this condition.

Johnson et al (2003) have provided us with a comprehensive list of possible unfavourable outcomes, but a more measured picture of the many difficulties that face both clients and health care professionals in this area would have better informed the Journal's readership.

Ford, C. \& Hepburn, M. (1997) Caring for the pregnant drug user. In Care of Drug Users in General Practice: A Harm-Minimisation Approach (ed. B. Beaumont), pp. 107-122. Oxford: Radcliffe Medical.

Johnson, K., Gerada, C. \& Greenough, A. (2003) Substance misuse during pregnancy. British Journal of Psychiatry, 183, 187-189.

Johnstone, F. (1998) Pregnant drug users. In Management of Drug Users in the Community: A Practical Handbook (ed. J. R. Robertson), pp. 299-327. London: Arnold.

Klee, H., Jackson, S. \& Lewis, S. (2002) Drug Misuse and Motherhood. London: Routledge.

A. Whittaker Primary Care Facilitator Team (HIV/Drugs), Lothian Primary Care NHS Trust, 22 Spittal Street, Edinburgh EH3 9DU, UK

C. McIntosh Rehabilitation Services, Royal Edinburgh Hospital, Morningside Road, Edinburgh EHIO 5HF, UK

Author's reply: We thank Drs Whittaker and McIntosh for their interest in our article, but they have misinterpreted its contents. As stated, the aim of our editorial was to emphasise the importance of the topic by describing the unfavourable effects illicit substances can have on both pregnancy and infant outcome; we are therefore pleased that Whittaker and McIntosh state we have provided a comprehensive list of unfavourable outcomes. We agree that treatment services should be accessible to women, as it is important to retain them throughout pregnancy and provide support through into the postnatal period. Indeed, in the final paragraph of our editorial we described such a package of care. We are surprised that Whittaker \& McIntosh feel that our article had an unsympathetic tone; careful reading of our editorial demonstrates that it emphasises the importance of optimising treatment and reducing morbidity and argues for adequate resources to be made available.

A. Greenough Department of Child Health, King's College Hospital, London SE5 9RS, UK

\section{Personality in psychiatry: what thin partitions?}

In his editorial on the interpersonal domain, Hobson (2003) asserts that the analysis of intersubjective engagement in the therapeutic dyad is essential to the understanding of subjective meanings and their role in the manifestation of psychiatric disorder. In the same issue of the Journal, Lanman et al (2003) describe their attempts to determine a measure of 'fit' between individuals in a 'couple system'.

Both these papers acknowledge a fundamental fact concerning all human relationships; that they are, in their totality, the interaction between one personality and another. What is striking, however, both in these papers and in other recent literature concerning, in particular, personality disorders (Tyrer et al, 2002), is the lack of any discussion concerning the specific role the therapist's/clinician's personality plays in shaping the therapeutic relationship.

Hobson's use of Donne's metaphor ('No man is an Island, entire of it self') captures what I believe to be the sine qua non of personality disorder; namely, that personality disorders can only be understood in the context of interactions between personalities; that the construct of personality disorder cannot exist in isolation. This notion is akin to the distinction made between 'primary' and 'secondary' qualities by the philosopher John Locke. In a psychiatric context one might consider schizophrenia to be a primary phenomenon, an integral part of the individual, whereas personality disorder, being contingent on an interaction with another, is secondary.
If one can accept the notion of personality disorder as a consequence of the interaction between two personalities, then surely it behoves members of the psychiatric profession to consider how their personalities influence the therapeutic relationships that lie at the heart of the discipline. That this appears, historically, not to have been the case is revealed by Lewis \& Appleby's (1988) seminal paper. While amply demonstrating psychiatrists' negative attitude towards individuals with personality disorder, the authors failed to address the possibility that this might be a function, in part, of the psychiatrists' personalities.

If we are to be 'scientific' about studying interpersonal functioning, then perhaps the first step might be to consider a systematic evaluation of both personalities involved in the therapeutic dyad. One possible method might employ a dimensional assessment of personality that would, in turn, help define how different personalities 'fit' together. For example it might be reasonable to expect a clinician, scoring highly on the 'openness' dimension of the NEO-PI-R (Costa \& McCrae, 1992) to fit well with a patient scoring much lower on the same scale.

If this were shown to be the case, it could have important ramifications for resource allocation, both in psychotherapy and in the wider psychiatric field, allowing individual personalities to be fitted together in order to better facilitate the therapeutic relationship. An appreciation of the role their own personalities play in the construct known as personality disorder, might also diminish psychiatrists' negative attitudes to the disorder they appear to dislike.

Costa, P. T. \& McCrae, R. R. (1992) Revised NEO Personality Inventory (NEO-PI-R) and NEO Five-Factor Inventory (NEO-FFI) Professional Manual. Odessa, FL: Psychological Assessment Resources.

Hobson, R. P. (2003) Between ourselves: psychodynamics and the interpersonal domain. British Journal of Psychiatry, 182, 193-195.

Lanman, M., Grier, F. \& Evans, C. (2003) Objectivity in psychoanalytic assessment of couple relationships. British Journal of Psychiatry, 182, 255-260.

Lewis, G. \& Appleby, L. (1988) Personality disorder: the patients psychiatrists dislike. British Journal of Psychiatry, 153, 44-49.

Tyrer, P., Duggan, C. \& Coid, J. (2002) Ramifications of personality disorder in clinical practice. British Journal of Psychiatry, 182 (suppl. 44), sl-s2.

T. Calton Department of Developmenta Psychiatry, Queen's Medical Centre, Nottingham NG7 2UH, UK 